\title{
Plasma NEFA storage in adipose tissue in the postprandial state: sex-related and regional differences
}

\author{
C. Koutsari • C. L. H. Snozek • M. D. Jensen
}

Received: 30 May 2008 / Accepted: 17 July 2008 / Published online: 19 August 2008

(C) Springer-Verlag 2008

\begin{abstract}
Aims/hypothesis We recently reported that a small fraction of circulating NEFA is stored through direct uptake in subcutaneous fat in postabsorptive humans in vivo and that this pathway may favour lower-body fat distribution in women. Here, we examined sex-related and regional differences in storage of plasma NEFA in subcutaneous adipose tissue during postprandial conditions.

Methods At $1 \mathrm{~h}$ after lunch, men and women of normal weight received an intravenous bolus of $\sim 1.66 \mathrm{MBq}\left[1-{ }^{14} \mathrm{C}\right]$ oleate followed by timed subcutaneous fat biopsies. The preceding breakfast was either a normal- or high-fat meal; the high-fat breakfast was used to create postprandial oleate concentrations in the postabsorptive range.

Results Storage of the NEFA tracer in adipose tissue $(\mathrm{dpm} / \mathrm{g}$ lipid) was greater in women; in both sexes abdominal fat stored tracer more avidly than femoral fat. A greater fraction of the administered tracer was stored in whole body subcutaneous fat of women than in that of men $(27 \pm 3$ vs $8 \pm$ $1 \%$, respectively, $p<0.0001$ ). No significant differences in tracer storage were observed between participants consuming the high- vs normal-fat breakfast.
\end{abstract}

C. Koutsari · M. D. Jensen $(\bowtie)$

Department of Internal Medicine/Division of Endocrinology,

Mayo Clinic College of Medicine,

5-194 Joseph,

Rochester, MN 55905, USA

e-mail: jensen.michael@mayo.edu

C. L. H. Snozek

Department of Laboratory Medicine and Pathology,

Mayo Clinic College of Medicine,

Rochester, MN, USA
Conclusions/interpretation Postprandial NEFA storage in subcutaneous fat through direct uptake accounts for $\sim 25 \%$ of NEFA disposal in women, but for $<10 \%$ in men in a wide range of circulating NEFA concentrations. It is greater in the upper- than lower-body subcutaneous fat, favouring upper-body fat accumulation in both sexes.

Keywords Abdominal · Adipose blood flow · Femoral · Oleate tracer $\cdot$ Subcutaneous $\cdot$ Triacylglycerol

$\begin{array}{ll}\text { Abbreviations } \\ \text { Apo } & \text { apolipoprotein } \\ \text { DXA } & \text { dual energy X-ray absorptiometry } \\ \text { GCRC } & \text { Mayo General Clinical Research Center } \\ \text { LBSQ } & \text { lower-body subcutaneous } \\ \text { LPL } & \text { lipoprotein lipase } \\ \text { TG } & \text { triacylglycerol } \\ \text { TGFA } & \text { triacylglycerol fatty acid } \\ \text { UBSQ } & \text { upper-body subcutaneous }\end{array}$

\section{Introduction}

In humans, adipose tissue gain or loss results from the balance between release of NEFA via lipolysis and the uptake/storage of fatty acids through the lipoprotein lipase (LPL) mechanism, such as with chylomicron and VLDLtriacylglycerol (TG), or from the direct uptake/storage of circulating NEFA. Direct NEFA storage has been observed in the postabsorptive [1] and the postprandial [2] states. We found that $\sim 4 \%$ of circulating NEFA were stored in subcutaneous adipose tissue in postabsorptive, normalweight men, whereas in normal-weight women the corresponding value was $\sim 8 \%$ [1]. The preferential storage of NEFA in upper body subcutaneous (UBSQ) fat in men, 
but not in women, suggests that this pathway may contribute to regulation of body fat distribution [1]. NEFA storage in upper and lower body subcutaneous (LBSQ) fat in humans in the postprandial state has not been assessed.

The aim of the present study was to understand whether there are sex-related and/or regional adipose tissue differences in NEFA storage in the postprandial state. We used an intravenously administered NEFA tracer to measure direct uptake/storage in UBSQ and LBSQ fat in men and women of normal weight. A high- or a normal-fat meal was provided $\sim 5 \mathrm{~h}$ prior to the study to allow us to examine the effect of plasma NEFA concentrations on this process.

\section{Methods}

Participants Normal-weight, healthy volunteers (17 men, 13 premenopausal women) participated in the study after providing written informed consent. The only medications allowed were oral contraceptives. The study was approved by the Mayo Clinic Institutional Review Board and the reported investigations were carried out in accordance with the principles of the Declaration of Helsinki as revised in 2000.

Study protocol Each volunteer consumed an isoenergetic diet (50\% carbohydrates, $35 \%$ fat, $15 \%$ protein) from the Mayo General Clinical Research Center (GCRC) for 3 days prior to the study to ensure weight stability and constant macronutrient intake. The volunteers were then admitted to the GCRC at 17:00 hours and given a meal at 18:00 hours. The next morning (study day), intravenous catheters were placed in a forearm vein in a heated hand vein (retrograde) for purposes of tracer infusion and arterialised venous blood sampling, respectively.

The study design is depicted in Fig. 1. On the study day, volunteers received research meals as part of a study of dietary fat metabolism [3]. Breakfast and lunch were consumed at $08: 00$ to $08: 30$ and $12: 30$ to $13: 00$ hours, respectively. The meals for each volunteer were consistent with their weight maintenance food intake during the previous 3 days. Volunteers were randomly assigned to receive an Ensure Plus (Abbott Laboratories, Columbus, OH, USA) breakfast providing energy equal to $40 \%$ of their individual resting energy expenditure (eight women, ten men) or the same meal plus $80 \mathrm{~g}$ triolein (five women, seven men). Thus, breakfast was either a normal-fat meal containing $\sim 15 \mathrm{~g}$ fat or a high-energy, high-fat meal containing $\sim 100 \mathrm{~g}$ fat.

At 13:15 hours, the volunteers received an intravenous bolus injection of $\sim 1.66 \mathrm{MBq}\left[1-{ }^{14} \mathrm{C}\right]$ oleate. The radioactivity in plasma NEFA and in non-chylomicron TG was determined by collecting blood samples before and after the $\left[1-{ }^{14} \mathrm{C}\right]$ oleate bolus. Subcutaneous abdominal and femoral fat biopsies were performed at $45 \mathrm{~min}$ (14:00 hours) after the $\left[1-{ }^{14} \mathrm{C}\right]$ oleate bolus. The biopsies were timed to ensure that virtually no NEFA tracer remained in the circulation, while not allowing sufficient time for tracer in VLDL-TG to accumulate in adipose tissue via the LPL pathway. We did not collect frequent early blood samples after the tracer injection because of blood volume withdrawal considerations and because the focus was on plasma radioactivity at the time of the biopsies (for timing of blood sampling, see Fig. 1).

Approximately $90 \mathrm{~min}$ before breakfast, $\sim 5.55 \mathrm{MBq}$ of ${ }^{133} \mathrm{Xe}$ was injected [4] in the abdominal subcutaneous and femoral adipose tissue beds. Blood flow was measured from the time of the injection until $\sim 1 \mathrm{~h}$ after lunch (13:30 hours). The data at $\sim 1 \mathrm{~h}$ after lunch are presented, as they correspond to the time of the $\left[1-{ }^{14} \mathrm{C}\right]$ oleate bolus.

Body composition measurements A single-slice computed tomography scan of the abdomen $\left(\mathrm{L}_{2-3}\right.$ interspace) in combination with dual energy $\mathrm{x}$-ray absorptiometry (DXA) (DPX-IQ; Lunar Radiation, Madison, WI, USA) was used to assess visceral fat mass [5]. LBSQ fat (from DXA) was considered fat caudal to the inguinal ligaments. UBSQ fat was calculated as total body fat (DXA) minus visceral and LBSQ fat.

Adipose tissue biopsies Subcutaneous adipose tissue samples were obtained by small needle liposuction under sterile conditions using local anaesthesia. Biopsies were taken from the abdominal (just lateral to the umbilicus) and the
Fig. 1 Schematic view of the study protocol. Subcutaneous adipose tissue biopsies were performed in the abdominal and femoral regions

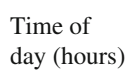

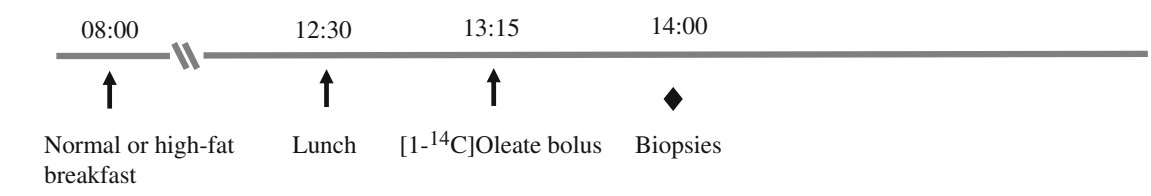

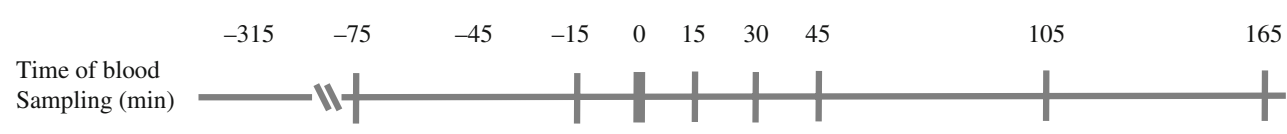


femoral (anterior-lateral aspect of the thigh, approximately one half the distance from the superior iliac spine to the patella) regions. The biopsy samples were immediately and meticulously rinsed with saline through Nitex Nylon Fiber 250/50 (Sefar America, Depew, NY, USA) and processed for measurement of adipocyte size and specific activity as described below. When possible, aliquots were stored at $-80^{\circ} \mathrm{C}$ for additional assays.

Measurement of adipocyte size and adipose tissue lipid specific activity Adipocyte size was assessed using a modification [6] of the approach of Di Girolamo et al. [7]. To measure adipose tissue lipid specific activity, the freshly rinsed tissue was added to $15 \mathrm{ml}$ chloroform:methanol (2:1 vol./vol.) and left in a cold room for at least 2 days.

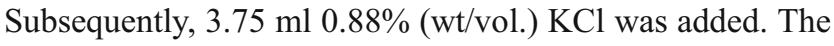
lipid layer was isolated by centrifugation, dried and weighed. The adipose specific activity (dpm/g lipid) from each biopsy was measured to less than $2 \%$ counting error.

Plasma oleate and non-chylomicron triacylglycerol specific activity Plasma oleate specific activity and concentration, and plasma palmitate concentration were measured by HPLC [8, 9]. To measure the appearance of the NEFA tracer into non-chylomicron $\mathrm{TG}, 0.8 \mathrm{ml}$ of fresh plasma from each time-point was layered underneath a density solution of $1.006 \mathrm{~g} / \mathrm{ml}$. The tubes were spun in a type 50.3 $\mathrm{Ti}$ rotor at $35,500 \mathrm{~g}$ for $30 \mathrm{~min}$ in an ultracentrifuge (Optima, LE-80K; Beckman Instruments, Spinco Division, Palo Alto, CA, USA). Chylomicrons were separated from the non-chylomicron fraction by slicing and aspirating the chylomicron layer. TG concentrations [10] were measured in a small portion of the non-chylomicron fraction and the remainder was subjected to Dole extraction to measure ${ }^{14} \mathrm{C}$ radioactivity. Non-chylomicron $\mathrm{TG}$ specific activity was expressed as dpm/ $\mu$ mol TG fatty acid (TGFA).

Assessment of the presence of VLDL particles in adipose tissue The biopsies were collected $45 \mathrm{~min}$ after the $\left[1-{ }^{14} \mathrm{C}\right]$ oleate bolus, a time when ${ }^{14} \mathrm{C}$ was found in plasma VLDLTG. To assess whether the ${ }^{14} \mathrm{C}$ we detected in whole adipose tissue samples was extracellular ${ }^{14} \mathrm{C}$-labelled VLDL rather than ${ }^{14} \mathrm{C}$-labelled fatty acids stored in adipocytes, we measured concentrations of apolipoprotein (Apo)B-100 in plasma and fat biopsies. We used abdominal and/or femoral adipose tissue samples available from eight men (eleven samples) and ten women (19 samples).

ApoB-100 in adipose tissue and plasma (collected at the time of the biopsy) was analysed using a multiplex immunoassay kit (LINCOplex, Millipore, St Charles, MO, USA) on a Luminex 100-IS (Luminex, Austin, TX, USA). Adipose biopsies (50-75 mg) were homogenised on ice in $1 \mathrm{ml}$ of the kit assay buffer (10 mmol/1 PBS, $0.08 \%$ (wt/vol.) sodium azide, $1 \%$ (wt/vol.) BSA, $\mathrm{pH} 7.4$ ). The homogenate was further diluted 25-fold in assay buffer to minimise assay interferences; $10 \mu \mathrm{l}$ of dilute homogenate was incubated in a 96-well plate with $25 \mu$ l of capture antibody-conjugated beads and $65 \mu \mathrm{l}$ assay buffer for $1 \mathrm{~h}$ ambient. Beads were washed (10 mmol/1 PBS, 0.05\% (vol./vol.) Proclin, 0.05\% (vol./vol.) Tween-20, $\mathrm{pH} 7.4$ ) and $50 \mu \mathrm{l}$ biotinylated detection antibody cocktail added for $30 \mathrm{~min}$ ambient, followed by further washing and incubation with $50 \mu \mathrm{l}$ streptavidin-phycoerythrin for $30 \mathrm{~min}$ ambient. After final washing, beads were resuspended in $150 \mu$ l Luminex sheath fluid for analysis.

A calibration curve of purified serum Apos was analysed alongside the samples to assign ApoB-100 concentrations. Standards were comprised of serial $\times 3$ dilutions ranging from $563 \mathrm{ng} / \mathrm{ml}$ to $2.32 \mathrm{ng} / \mathrm{ml}$; quadratic fitting was used to determine the regression equation. In addition to the calibrators, a series of adipose tissue samples was created to estimate the level of plasma contamination detectable in this assay. Aliquots $(75 \mathrm{mg}$ ) of adipose tissue were homogenised as described above, then spiked with $0,1,5$, 10 or $20 \mu \mathrm{l}$ plasma with mid-range ApoB-100 concentrations and analysed alongside the study samples. With the addition of $5 \mu$ of plasma, Apo-B100 became detectable. With this degree of sensitivity, we were able to detect a $\sim 5 \%$ contamination of the adipose tissue with ${ }^{14} \mathrm{C}$-labelled VLDL.

For the conversion of total ApoB-100 to VLDLApoB-100, we assumed that VLDL-ApoB-100 comprises $\sim 8 \%$ of total circulating ApoB-100 [11]. To calculate the fraction of adipose tissue lipid ${ }^{14} \mathrm{C}$ attributable to VLDL particles in the tissue sample, we assessed the amount of ${ }^{14} \mathrm{C}$ per $\mu \mathrm{mol}$ VLDL (dpm/ $\mu \mathrm{mol}$ VLDL) by dividing the amount of non-chylomicron ${ }^{14} \mathrm{C}$ radioactivity per $\mathrm{ml}$ plasma by the $\mu \mathrm{mol}$ of VLDL per ml plasma.

Distribution of ${ }^{14} \mathrm{C}$ in NEFA vs fatty acid ester fractions in adipose tissue We previously found that the majority of NEFA tracer present in adipocytes is in the form of TG [1]. In contrast, whole adipose tissue samples (rather than isolated adipocytes) collected early after the tracer injection contained radioactivity in the NEFA fraction (i.e. tracer not taken up and stored in adipocytes) [1]. To test whether the whole adipose tissue samples used in the present study contained tracer in the form of NEFA, we separated the NEFA from the fatty-acid esters [12]. Briefly, the lipid extracts from the 30 samples used for ApoB-100 measurements were dissolved in $4 \mathrm{ml}$ heptane and then washed by shaking twice with 10 and $5 \mathrm{ml}$ of $100 \mathrm{mmol} / \mathrm{l} \mathrm{NaOH}$ in $50 \%$ (vol./vol.) ethanol, respectively. Both the NEFA (heptane) and fatty-acid esters fractions were collected. The alkaline ethanol fraction was re-washed twice with $8 \mathrm{ml}$ of heptane to remove any residual fatty-acid esters, which were subsequently combined with the previously collected fatty-acid esters fraction. The NEFA and fatty- 
acid esters fractions were dried down and counted. Because NEFA counts might be undetectable in the small amounts of tissue available from most of the volunteers (27 of 30 samples), we pooled the small samples of the same sex and depot together. This was done to ensure that NEFA counts would be detectable in the pooled samples; however, if NEFA counts were detected, we would not know which specific sample(s) were responsible. Three samples were big enough to provide detectable NEFA counts if present and were measured individually.

Glucose and insulin concentrations Plasma glucose concentrations were measured using a glucose analyser (Beckman Instruments, Fullerton, CA, USA). Plasma insulin concentrations were measured using a chemiluminescence method with an assay system (Access Ultrasensitive Immunoenzymatic; Beckman, Chaska, MN, USA)

Materials We purchased $\left[1-{ }^{14} \mathrm{C}\right]$ oleate from NEN Life Science Products, PerkinElmer, Boston, MA, USA. We dissolved ${ }^{133} \mathrm{Xe}$ (Syncor, St Paul, MN, USA) in sterile saline and used it to measure regional adipose tissue blood flow.

Calculations The oleate tracer concentration in adipose tissue (dpm/g adipose lipid) was multiplied by the depotspecific fat mass (g) to derive dpm per depot. The quantity of NEFA tracer (dpm) in a fat depot was divided by the quantity of tracer (dpm) administered to calculate the fraction of NEFA stored in that depot. NEFA tracer storage is presented both as dpm/g adipose lipid (specific activity) and as a percentage of the NEFA tracer administered. Because the dose of the NEFA tracer administered was similar for all volunteers $(\sim 1.66 \mathrm{MBq})$, it was possible to compare the regional specific activity among participants.

Statistics Values are reported as means \pm SE. ANOVA showed that breakfast fat content did not have a significant effect on any of the variables studied (with the exception of plasma oleate concentrations). Consequently, subsequent statistical analyses were performed without including breakfast fat content as an independent variable. Sex and time effects on non-chylomicron-TG, plasma oleate, glucose and insulin concentrations, and plasma oleate and nonchylomicron TGFA specific activity were assessed with repeated measures ANOVA. Two-tailed unpaired Student's $t$ test was used to compare participants' characteristics, postprandial adipose tissue blood flow and NEFA tracer storage between sexes. Adipocyte cell size, postprandial adipose tissue blood flow and NEFA storage were compared between depots using two-tailed paired Student's $t$ test. A $5 \%$ level of significance was adopted throughout. Statistical analyses were performed using Statistica version 7.0 (StatSoft, Tulsa, OK, USA).

\section{Results}

Participant characteristics The two groups had similar age and BMI, but women, as expected, had more body fat (except visceral fat) than men (Table 1). Abdominal and femoral adipocyte size was not significantly different between men and women. In women, femoral adipocytes were significantly larger than abdominal adipocytes.

Plasma oleate, palmitate, insulin and glucose concentrations Plasma oleate and palmitate concentrations before and after the $\left[1-{ }^{14} \mathrm{C}\right]$ oleate bolus are shown in Fig. 2a,b, respectively. Glucose and insulin concentrations are shown in Fig. 3a,b, respectively. The average palmitate concentrations were not significantly different between the high-fat $(41 \pm 6 \mu \mathrm{mol} / \mathrm{l})$ and normal-fat $(34 \pm 6 \mu \mathrm{mol} / \mathrm{l})$ meal groups ( $p=0.10$ for effect of meal) (Fig. 2b). In contrast, the average oleate concentrations over the $30 \mathrm{~min}$ after the bolus were greater in the participants who had received the high-fat breakfast than in those who had consumed the normal-fat breakfast $(206 \pm 32$ vs $76 \pm 14 \mu \mathrm{mol} / 1, p<0.0001)$ (Fig. 2a). The greater post-lunch oleate concentrations following the high-fat breakfast (containing $80 \mathrm{~g}$ of triolein) were, at least partly, the result of spillover of dietary/chylomicron oleate into the systemic NEFA pool. There were no significant sexrelated differences in oleate $(p=0.27)$, palmitate $(p=0.33)$, glucose $(p=0.42)$ or insulin $(p=0.10)$ responses.

Plasma oleate and non-chylomicron TGFA specific activity The amount of $\left[1-{ }^{14} \mathrm{C}\right]$ oleate received by the women and men was $1.74 \pm 0.07 \mathrm{MBq}$ and $1.66 \pm 0.07 \mathrm{MBq}$, respectively $(p=0.66)$. The oleate specific activity was elevated at the time of the first blood sample following the tracer injection, i.e. at $15 \mathrm{~min}$ after the bolus (Fig. $4 \mathrm{a}$ ). Plasma $\left[1-{ }^{14} \mathrm{C}\right]$ oleate radioactivity at the time of the biopsies was very low (range

Table 1 Anthropometrics, body fat distribution and adipocyte size of the study participants

\begin{tabular}{|c|c|c|c|}
\hline Characteristics & Women $(n=13)$ & Men $(n=17)$ & $p$ value \\
\hline Age (years) ${ }^{\mathrm{a}}$ & $33 \pm 2$ & $29 \pm 2$ & \\
\hline BMI $\left(\mathrm{kg} / \mathrm{m}^{2}\right)^{\mathrm{a}}$ & $22.2 \pm 0.6$ & $23.3 \pm 0.4$ & \\
\hline Weight (kg) & $62.1 \pm 2.1$ & $76.7 \pm 2.2$ & 0.0001 \\
\hline Total body fat (\%) & $30.6 \pm 1.7$ & $17.6 \pm 1.2$ & $<0.0001$ \\
\hline Total body fat $(\mathrm{kg})$ & $18.2 \pm 1.4$ & $11.8 \pm 0.9$ & $<0.0001$ \\
\hline UBSQ fat $(\mathrm{kg})$ & $9.5 \pm 0.7$ & $6.1 \pm 0.5$ & 0.0001 \\
\hline LBSQ fat (kg) & $7.6 \pm 0.6$ & $4.2 \pm 0.3$ & $<0.0001$ \\
\hline Visceral fat (kg) & $1.2 \pm 0.2$ & $1.6 \pm 0.2$ & 0.08 \\
\hline \multicolumn{4}{|c|}{ Adipocyte size ( $\mu \mathrm{g}$ lipid/cell) } \\
\hline Abdominal & $0.41 \pm 0.06$ & $0.52 \pm 0.07$ & 0.23 \\
\hline Femoral & $0.62 \pm 0.05^{\mathrm{b}}$ & $0.62 \pm 0.07$ & 0.98 \\
\hline
\end{tabular}

Values are means $\pm \mathrm{SE}$

${ }^{a}$ Selected to be similar and not subject to statistical testing

${ }^{\mathrm{b}} p<0.01$ vs abdominal adipocyte size by paired Student's $t$ test 


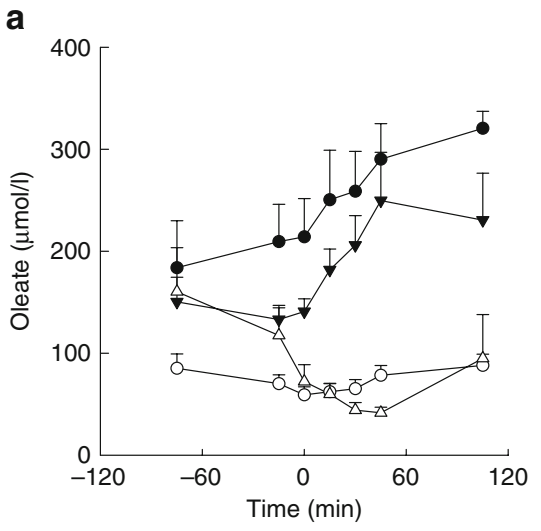

Fig. 2 Plasma oleate (a) and palmitate (b) concentrations before and after the intravenous $\left[1-{ }^{14} \mathrm{C}\right]$ oleate bolus at time zero. Note the different scales of the $y$-axes. A meal (lunch) was consumed at -45 to $-15 \mathrm{~min}$. Subcutaneous abdominal and femoral adipose tissue biopsy samples were collected at $45 \mathrm{~min}$ after the tracer bolus. Triangles,

18-98 dpm/ml) (Fig. 4a) and did not differ between sexes $(p=0.92)$. These low values confirm that the fat biopsies were collected when virtually all $\left[1-{ }^{14} \mathrm{C}\right]$ oleate had been cleared from the circulation. There were no significant effects of breakfast fat content ( $p=0.24$ for effect of meal) or sex $(p=0.08)$ on the oleate specific activity response.

${ }^{14} \mathrm{C}$ was detected in non-chylomicron TGFA at $30 \mathrm{~min}$ after the $\left[1-{ }^{14} \mathrm{C}\right]$ oleate bolus and peaked on average at $105 \mathrm{~min}$ (Fig. 4b). No significant sex- $(p=0.08)$ or mealrelated $(p=0.24)$ differences were seen. Non-chylomicron TG concentrations are shown in Fig. 4c. No statistically significant effect of breakfast fat content was seen $(p=$ $0.14)$, but men tended to have greater concentrations than women $(p=0.052)$.

NEFA storage in subcutaneous adipose tissue We were unable to collect sufficient amounts of femoral fat from

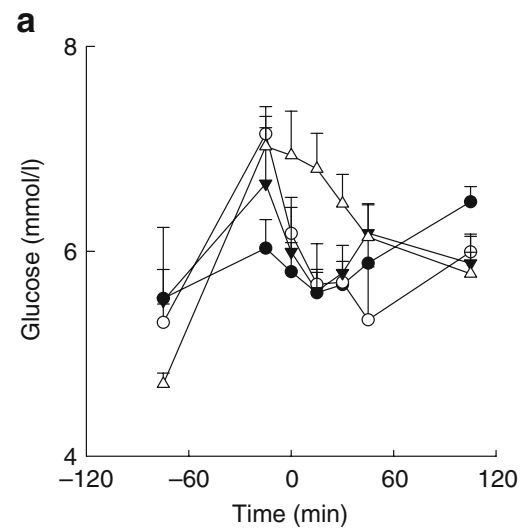

Fig. 3 Plasma glucose (a) and insulin (b) concentrations before and after the intravenous $\left[1-{ }^{14} \mathrm{C}\right]$ oleate bolus at time zero. A meal (lunch) was consumed at -45 to $-15 \mathrm{~min}$. Subcutaneous abdominal and femoral adipose tissue biopsy samples were collected at $45 \mathrm{~min}$ after the tracer bolus. Triangles, values for women; circles, values for men; black

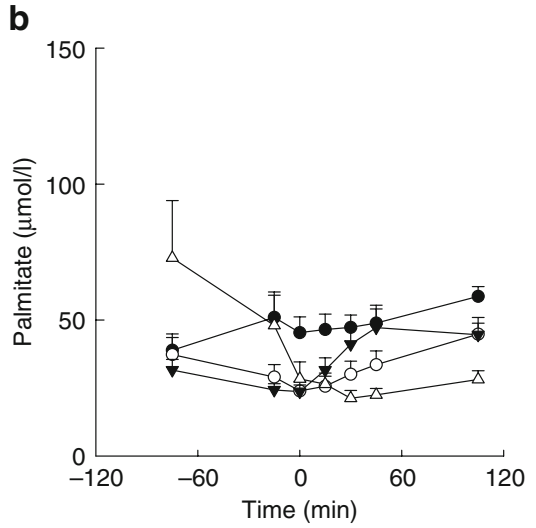

values for women; circles, values for men; black symbols, data for participants consuming the high-fat breakfast; white symbols, data for participants consuming the normal-fat breakfast. Values are means \pm SE. For statistical comparisons, see the "Results" section

three of the men for measurement of adipose lipid specific activity. Specific activity values and the fractions of the NEFA tracer stored in subcutaneous fat are provided in Table 2.

The average adipose lipid specific activity values in both abdominal subcutaneous and femoral fat were significantly greater in women than in men (UBSQ fat, $p=0.018$; LBSQ fat, $p=0.0003)$. Abdominal specific activity was greater than femoral specific activity in women $(p=0.01)$ and men $(p=0.01)$; in both sexes a significantly greater fraction of $\left[1-{ }^{14} \mathrm{C}\right]$ oleate was stored in the UBSQ than in LBSQ fat $(p<0.001)$. Women stored greater proportions of the NEFA tracer in UBSQ, LBSQ and total subcutaneous fat $(p<$ 0.0001 women vs men for all). The adipose lipid specific activity and the per cent of tracer stored in adipose tissue were not significantly different between participants who had received the normal-fat and those who had received the

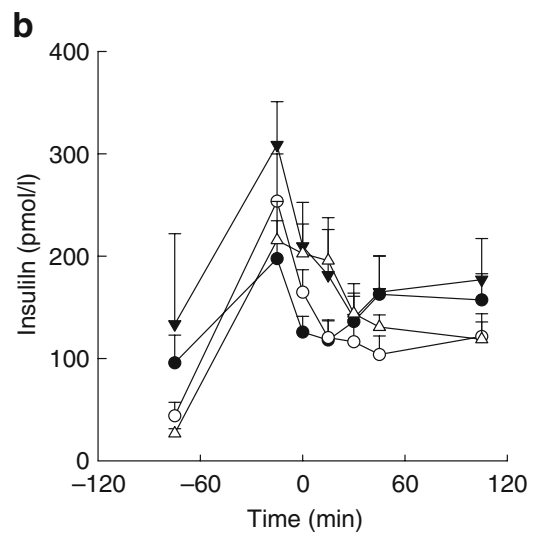

symbols, data for participants consuming the high-fat breakfast; white symbols, data for participants consuming the normal-fat breakfast. Values are means $\pm \mathrm{SE}$. For statistical comparisons, see the "Results" section 
a

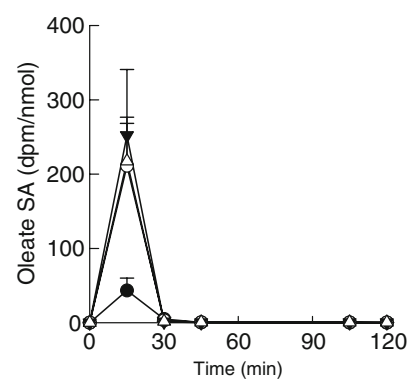

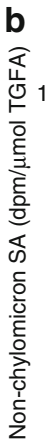

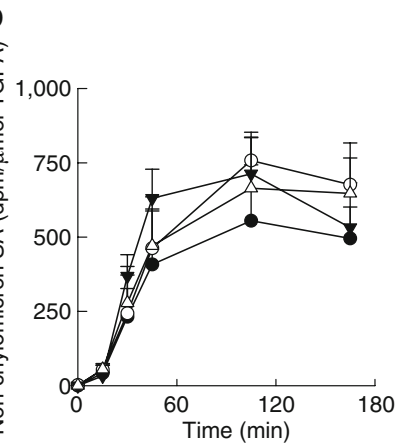

C

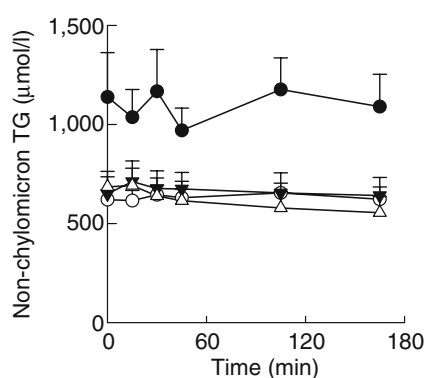

Fig. 4 Time-course of plasma oleate specific activity (SA) (a), nonchylomicron TGFA SA (b), and non-chylomicron TG concentration (c) after the intravenous $\left[1-{ }^{14} \mathrm{C}\right]$ oleate bolus at time zero. A meal (lunch) was consumed at -45 to $-15 \mathrm{~min}$ (not depicted). Subcutaneous abdominal and femoral adipose tissue biopsies were collected at

high-fat breakfast, despite the markedly different plasma oleate concentrations (Fig. 2a).

Presence of VLDL particles in adipose tissue samples In 26 out of 30 tissue samples ApoB-100 was below the lowest detection limit $(2.32 \mathrm{ng} / \mathrm{ml})$. To these samples, we assigned an ApoB-100 concentration of $2.30 \mathrm{ng} / \mathrm{ml}$, and therefore our estimates of the amount of VLDL in whole, washed adipose tissue are conservative.

Based upon the dpm in non-chylomicron TG relative to plasma VLDL ApoB-100 and the concentration of VLDL ApoB-100 in whole adipose tissue, we estimated that $10 \pm$ $2 \%$ of the ${ }^{14} \mathrm{C}$ in adipose tissue lipid could be attributed to VLDL particles. In nine women, we were able to assess the presence of VLDL in the abdominal and femoral samples. The average adipose lipid specific activity in abdominal subcutaneous and femoral fat, as well as the fractional $\left[1-{ }^{14} \mathrm{C}\right]$ oleate storage (\% of tracer administered) before and after correcting for contribution of VLDL-TG, is presented in Table 3. The contribution of VLDL to ${ }^{14} \mathrm{C} \mathrm{dpm}$ in

Table 2 Specific activity of ${ }^{14} \mathrm{C}$ and percentage of the administered $\left[1-{ }^{14} \mathrm{C}\right]$ oleate that was stored in UBSQ and LBSQ fat in women and men at $45 \mathrm{~min}$ after the intravenous bolus injection of $\sim 1.66 \mathrm{MBq}$ $\left[1-{ }^{14} \mathrm{C}\right]$ oleate

\begin{tabular}{llll}
\hline Variables & Women & Men & $\begin{array}{l}p \text { value, } \\
\text { sex }\end{array}$ \\
\hline Specific activity (dpm/g lipid) & & \\
UBSQ fat & $1,873 \pm 214$ & $1,122 \pm 202$ & $<0.05$ \\
LBSQ fat & $1,425 \pm 168^{\mathrm{a}}$ & $605 \pm 97^{\mathrm{a}}$ & $<0.001$ \\
NEFA tracer take-up (\%) & & & \\
UBSQ fat & $16.4 \pm 1.5$ & $5.8 \pm 0.8$ & $<0.0001$ \\
LBSQ fat & $10.4 \pm 1.5^{\mathrm{b}}$ & $2.5 \pm 0.4^{\mathrm{b}}$ & $<0.0001$ \\
Whole body & $26.8 \pm 2.7$ & $8.2 \pm 1.0$ & $<0.0001$ \\
$\quad$ subcutaneous fat & & & \\
\hline
\end{tabular}

Values are means $\pm \mathrm{SE}$

${ }^{\mathrm{a}} p=0.01,{ }^{\mathrm{b}} p<0.001$ vs corresponding value in UBSQ fat
$45 \mathrm{~min}$ after the tracer bolus. Triangles, values for women; circles, values for men; black symbols, data for participants consuming the high-fat breakfast; white symbols, data for participants consuming the normal-fat breakfast. Values are means \pm SE. For statistical comparisons, see the "Results" section

adipose tissue lipid was relatively small and, even after correction, women maintained preferential accumulation of the NEFA tracer in the UBSQ region.

Distribution of the NEFA tracer in NEFA vs fatty-acid esters fractions in adipose tissue In the individual $(n=3)$ and pooled adipose samples, $<1 \%$ of the adipose tissue lipid ${ }^{14} \mathrm{C}$ counts were in the NEFA fraction; the remainder were in the fatty-acid esters fraction. Thus, radioactivity in whole adipose tissue from these volunteers was $\sim 90 \%$ in fatty acids that had been esterified into complex lipids and were not VLDL-TG.

Adipose tissue blood flow Abdominal subcutaneous or leg adipose tissue blood flow data were not available in four of the women and four of the men. Abdominal adipose tissue blood flow measured at $\sim 15 \mathrm{~min}$ after the $\left[1{ }^{14} \mathrm{C}\right]$ oleate bolus was $6.6 \pm 1.3$ vs $3.9 \pm 0.9 \mathrm{ml}(100 \mathrm{~g} \text { tissue })^{-1} \mathrm{~min}^{-1}$ $(p=0.09)$ in women and men, respectively. Corresponding femoral adipose tissue blood flow values were $4.8 \pm 1.1$ vs $4.4 \pm 1.1 \mathrm{ml}(100 \mathrm{~g} \text { tissue })^{-1} \min ^{-1}(p=0.88)$.

Table 3 Specific activity of ${ }^{14} \mathrm{C}$ and percentage of the administered $\left[1-{ }^{14} \mathrm{C}\right]$ oleate that was stored in UBSQ and LBSQ fat in nine women before and after correcting for the presence of VLDL in tissue at $45 \mathrm{~min}$ after the intravenous bolus injection of $\sim 1.66 \mathrm{MBq}\left[1-{ }^{14} \mathrm{C}\right]$ oleate

\begin{tabular}{lcc}
\hline Variables & Uncorrected & Corrected \\
\hline Specific activity (dpm/g lipid) & & \\
UBSQ fat & $1,847 \pm 244$ & $1,751 \pm 263$ \\
LBSQ fat & $1,392 \pm 237$ & $1,246 \pm 236$ \\
NEFA tracer stored (\%) & & \\
UBSQ fat & $18.3 \pm 1.6$ & $17.3 \pm 1.6$ \\
LBSQ fat & $11.3 \pm 2.0$ & $10.2 \pm 2.0$ \\
WBSQ fat & $29.6 \pm 3.3$ & $27.5 \pm 3.4$ \\
\hline
\end{tabular}

Values are means $\pm \mathrm{SE}$

WBSQ, whole body subcutaneous 


\section{Discussion}

We present the contributions of UBSQ and LBSQ fat to NEFA disposal in the postprandial state. Adipose tissue biopsies were collected from women and men of normal weight at a time reflecting storage of the plasma NEFA tracer through a direct uptake mechanism. Approximately $27 \%$ of the administered NEFA tracer was stored in subcutaneous fat in women, whereas in men only $\sim 8 \%$ was stored via this pathway, indicating major differences in NEFA disposal into adipose tissue. In comparison with the postabsorptive state [1], these values represent approximately threefold and twofold increases in the fraction of NEFA stored in subcutaneous fat in normal-weight women and men, respectively. As in the postabsorptive state [1], NEFA tracer storage per unit adipose lipid mass was greater in women than men. In the postprandial state both sexes showed preferential accumulation of the NEFA tracer in their UBSQ fat region.

Disappearance of NEFA across abdominal adipose tissue has been detected in postprandial men using a combination of stable isotope dilution and arterio-venous balance techniques [2]. We administered the NEFA tracer and performed the fat biopsies after a noon meal, a time of significant chylomicronaemia. Coordinated LPL action on chylomicron-TG in the adipose tissue capillary bed, combined with insulin-mediated inhibition of adipose tissue lipolysis, creates a favourable concentration gradient that facilitates the inward flow of fatty acids (LPL-derived and plasma NEFA) into adipocytes. One possible explanation for the greater fraction of plasma NEFA stored in adipose tissue in the fed state than in the postabsorptive state [1] is that adipose tissue has the same storage $(\mu \mathrm{mol} / \mathrm{min})$ of a smaller pool (reduced NEFA concentrations in the postprandial period due to insulin-mediated inhibition of lipolysis). Alternatively, there may be an enhanced NEFA transmembrane transport (as passive diffusion and/or facilitated transport), combined with accelerated intracellular fatty acid sequestration as TG, in the postprandial state. Our finding that the fractional NEFA tracer storage was similar in those participants with postabsorptive range plasma oleate concentrations as a result of consuming the high-fat breakfast (Fig. 2a) suggests that enhanced postprandial NEFA storage is independent of circulating NEFA concentrations.

Given that plasma oleate concentrations in participants consuming the high-fat breakfast were three- to fivefold greater than in the normal-fat breakfast group (Fig. 2a), yet the fractional oleate tracer storage in subcutaneous fat was similar, the absolute oleate storage must also have been much greater in the high-fat meal group. The greater chylomicronaemia after the high-fat breakfast [3] may have created a greater local concentration of LPL-derived fatty acids, and thus a more favourable concentration gradient for the inward flow of circulating NEFA into adipocytes, explaining the greater absolute oleate storage in the highfat breakfast group. This novel observation suggests that the direct NEFA storage pathway may be an important route for the disposal of LPL-generated NEFA spilling over into the systemic circulation in the postprandial state; up to one third of meal fatty acids traverse the NEFA pool during the postprandial interval [13-15].

Women had greater adipose lipid specific activity $(\mathrm{dpm} / \mathrm{g}$ adipose lipid) and amount of body fat than men. Therefore, women stored a greater fraction of the NEFA tracer in their subcutaneous fat than did men. No statistically significant differences in adipocyte size or blood flow between sexes were found, suggesting that factors other than or in addition to substrate delivery or fat cell size account for the sex-related differences we observed. Little is known about the potential mechanism(s) for this sex-related difference. Possible explanations include: (1) greater postprandial adipose tissue LPL activity in women [3], resulting in a more favourable inward concentration gradient; (2) a more active facilitated fatty acid transport system; and (3) more efficient TG synthesis in adipocytes of women [16], which would lower the intracellular NEFA concentration.

In both sexes, $\left[1-{ }^{14} \mathrm{C}\right]$ oleate storage per unit lipid mass was greater in abdominal subcutaneous fat than in femoral fat. This contrasts with postabsorptive women, in whom no preferential upper body NEFA storage was noted [1]. The greater NEFA storage in abdominal subcutaneous fat in our normal-weight men and women corresponds with the greater meal fatty acid storage by abdominal subcutaneous fat in normal-weight humans $[4,17]$. Given the much larger quantities of chylomicron-derived fatty acids than NEFA entering adipocytes in the postprandial period, the direct NEFA storage we measured may, to some extent, be a reflection of the pathway of dietary fatty acid uptake/ storage by adipocytes.

The limitations of our study need to be taken into consideration. Our goal was to time the biopsies such that virtually no $\left[1-{ }^{14} \mathrm{C}\right]$ oleate would be in the circulation and tracer levels in VLDL-TG would be insufficient to allow accumulation in adipose tissue. This can be challenging because the NEFA tracer appears as VLDL-TGFA before it is completely cleared from the circulation (Fig. 4b). Although it is possible that VLDL-derived $\left[1-{ }^{14} \mathrm{C}\right]$ oleate was stored in adipose tissue via the LPL pathway, this seems unlikely to have affected our results, given the slow disappearance rate of VLDL-TG from the circulation [18] and the fact that $<10-15 \%$ of systemic NEFA are converted to VLDL-TG over several hours $[19,20]$. Although some of the radioactivity in the adipose tissue samples may have been ${ }^{14} \mathrm{C}$-labelled VLDL present in adipose tissue capillaries (i.e. extracellular), the amount of $\mathrm{ApoB}$ in the tissue 
indicated that VLDL contributed $\leq 10 \%$ of the ${ }^{14} \mathrm{C}$ present in adipose tissue lipid. Even after correcting for this artefact, $\left[1-{ }^{14} \mathrm{C}\right]$ oleate storage still represented nearly threefold (women) and twofold (men) increases from the postabsorptive state [1]. Another limitation is that we assessed regional NEFA tracer storage by extrapolating from para-umbilical and femoral subcutaneous fat samples to the UBSQ and LBSQ depots, respectively. Studies of direct NEFA storage in a variety of subcutaneous adipose tissue beds are needed to understand the limits to the accuracy of this extrapolation.

These findings emphasise the role of subcutaneous fat in direct plasma NEFA storage, confirming that storage occurs in postprandial men [2] and defining sex-related and regional differences in this process. We found that direct NEFA storage in subcutaneous fat is a quantitatively more important pathway in postprandial women than in men, accounting for over one quarter of NEFA disposal. Interestingly, fractional storage of NEFA in adipose tissue is not greater in the postprandial state merely because plasma NEFA concentrations are low. Direct postprandial NEFA storage per unit lipid weight is greater in UBSQ than in LBSQ fat in men and women (unlike the postabsorptive condition), suggesting that the direct NEFA storage process in the fed state favours upper-body fat accumulation in both sexes.

Acknowledgements This work was supported by grants DK40484, DK45343, DK50456 and R00585 from the U.S. Public Health Service and by the Mayo Foundation. We thank the research volunteers for their participation. We also thank J. Eastman, D. Harteneck, D. Lucas, C. Siverling, L. Zhou and the Mayo Clinic GCRC staff for their technical assistance and help with data collection. A portion of this work was presented at the Annual Scientific meeting of the North American Association for the Study of Obesity, in Las Vegas, NV, USA, in November 2004.

Duality of interest The authors declare that there is no duality of interest associated with this manuscript.

\section{References}

1. Shadid S, Koutsari C, Jensen MD (2007) Direct free fatty acid uptake into human adipocytes in vivo: relation to body fat distribution. Diabetes 56:1369-1375

2. Bickerton AS, Roberts R, Fielding BA et al (2007) Preferential uptake of dietary fatty acids in adipose tissue and muscle in the postprandial period. Diabetes 56:168-176
3. Votruba SB, Jensen MD (2006) Sex-specific differences in leg fat uptake are revealed with a high-fat meal. Am J Physiol Endocrinol Metab 291:E1115-E1123

4. Romanski SA, Nelson R, Jensen MD (2000) Meal fatty acid uptake in adipose tissue: Gender effects in non-obese humans. Am J Physiol 279:E455-E462

5. Jensen MD, Kanaley JA, Reed JE, Sheedy PF (1995) Measurement of abdominal and visceral fat with computed tomography and dualenergy X-ray absorptiometry. Am J Clin Nutr 61:274-278

6. Tchoukalova YD, Harteneck DA, Karwoski RA, Tarara J, Jensen MD (2003) A quick, reliable, and automated method for fat cell sizing. J Lipid Res 44:1795-1801

7. Di Girolamo M, Mendlinger S, Fertig JW (1971) A simple method to determine fat cell size and number in four mammalian species. Am J Physiol 221:850-858

8. Miles JM, Ellman MG, McClean KL, Jensen MD (1987) Validation of a new method for determination of free fatty acid turnover. Am J Physiol 252:E431-E438

9. Jensen MD, Rogers PJ, Ellman MG, Miles JM (1988) Choice of infusion-sampling mode for tracer studies of free fatty acid metabolism. Am J Physiol 254:E562-E565

10. Humphreys SM, Fisher RM, Frayn KN (1990) Micromethod for measurement of sub-nanomole amounts of triacylglycerol. Ann Clin Biochem 27:597-598

11. Welty FK, Lichtenstein AH, Barrett PH, Dolnikowski GG, Schaefer EJ (1999) Human apolipoprotein (Apo) B-48 and ApoB-100 kinetics with stable isotopes. Arterioscler Thromb Vasc Biol 19:2966-2974

12. Kerpel S, Shafrir E, Shapiro B (1961) Mechanism of fatty acid assimilation in adipose tissue. Biochim Biophys Acta 46:495-504

13. Roust LR, Jensen MD (1993) Postprandial free fatty acid kinetics are abnormal in upper body obesity. Diabetes $42: 1567-1573$

14. Miles JM, Park YS, Walewicz D et al (2004) Systemic and forearm triglyceride metabolism: fate of lipoprotein lipasegenerated glycerol and free fatty acids. Diabetes 53:521-527

15. Barrows BR, Timlin MT, Parks EJ (2005) Spillover of dietary fatty acids and use of serum nonesterified fatty acids for the synthesis of VLDL-triacylglycerol under two different feeding regimens. Diabetes 54:2668-2673

16. Edens NK, Fried SK, Kral JG, Hirsch J, Leibel RL (1993) In vitro lipid synthesis in human adipose tissue from three abdominal sites. Am J Physiol 265:E374-E379

17. Uranga AP, Levine J, Jensen M (2005) Isotope tracer measures of meal fatty acid metabolism: reproducibility and effects of the menstrual cycle. Am J Physiol 288:E547-E555

18. Mittendorfer B, Patterson BW, Klein S (2003) Effect of sex and obesity on basal VLDL-triacylglycerol kinetics. Am J Clin Nutr 77:573-579

19. Friedberg SJ, Klein RF, Trout DL, Bogdonoff MD, Estes EH Jr. (1961) The incorporation of plasma free fatty acids into plasma triglycerides in man. J Clin Invest 4:1846-1855

20. Havel RJ, Kane JP, Balasse EO, Segel N, Basso LV (1970) Splanchnic metabolism of free fatty acids and production of triglycerides of very low density lipoproteins in normotriglyceridemic and hypertriglyceridemic humans. J Clin Invest 49:2017-2035 